\title{
Branched RNA: A New Architecture for RNA Interference
}

\author{
Anna Aviñó, ${ }^{1}$ Sandra M. Ocampo, ${ }^{1}$ José Carlos Perales, ${ }^{2}$ and Ramon Eritja ${ }^{1}$ \\ ${ }^{1}$ Institute for Research in Biomedicine (IRB Barcelona), Institute of Advanced Chemistry of Catalonia (IQAC-CSIC), \\ Networking Centre on Bioengineering, Biomaterials, and Nanomedicine (CIBER-BBN), Baldiri Reixac 10, 08028 Barcelona, Spain \\ ${ }^{2}$ Department of Physiological Sciences, School of Medicine, University of Barcelona (Campus Bellvitge), Feixa Llarga, \\ L'Hospitalet de Llobregat, 08907 Barcelona, Spain
}

Correspondence should be addressed to Ramon Eritja, recgma@cid.csic.es

Received 16 October 2010; Accepted 14 January 2011

Academic Editor: Arthur van Aerschot

Copyright (C) 2011 Anna Aviñó et al. This is an open access article distributed under the Creative Commons Attribution License, which permits unrestricted use, distribution, and reproduction in any medium, provided the original work is properly cited.

\begin{abstract}
Branched RNAs with two and four strands were synthesized. These structures were used to obtain branched siRNA. The branched siRNA duplexes had similar inhibitory capacity as those of unmodified siRNA duplexes, as deduced from gene silencing experiments of the TNF- $\alpha$ protein. Branched RNAs are considered novel structures for siRNA technology, and they provide an innovative tool for specific gene inhibition. As the method described here is compatible with most RNA modifications described to date, these compounds may be further functionalized to obtain more potent siRNA derivatives and can be attached to suitable delivery systems.
\end{abstract}

\section{Introduction}

In recent years, siRNAs have generated tremendous interest in therapeutics [1]. Nevertheless, the transition of siRNAs from the laboratory to the clinical practice has encountered several obstacles. Briefly, siRNA duplexes are rapidly degraded in serum by exonucleases and endonucleases [2]. The polyanionic phosphodiester backbone of siRNA suffers from difficult cell uptake [3], and oligonucleotides may have off-target effects, either by stimulating the immune system [4] or by entering other endogenous gene regulation pathways [5]. Several chemical modifications have been proposed in the literature to address these drawbacks [2-4]. Most of these modifications are based on modified nucleosides and changes on backbone linkages [6, 7]. Thus, changes in sugar moiety influences sugar conformation, and, therefore, overall siRNA structure. Modifications of the $2^{\prime}-\mathrm{OH}$ by $\mathrm{F}$ or $\mathrm{OMe}$ as well as LNA $[8,9]$ are well tolerated and improve binding affinity and nuclease resistance. Base modifications that stabilize base pairs (5-bromouracil, 5-methylcytosine, 5-propynyluracil, and others) have also been proposed $[7,10]$. Terminal conjugates, especially at the termini of the sense strand, have been modified with a large number of lipids to achieve improved cellular uptake [11].
In addition to these modifications, siRNA architecture is also crucial in the design of effective and specific siRNA. The architecture itself can be altered by chemical synthesis. In addition to the canonical siRNA architecture of 21-nt antiparallel, double-strand RNA with 2-nt 3 '-overhangs [12], several forms of siRNA have been described. Bluntended siRNA [13], 25/27 mer Dicer-substrate or asymmetric siRNA [14] are among the siRNA structures formed by two strands. Moreover, functional siRNA can also be formed by one single RNA strand. This is the case in small hairpin RNA (shRNA), where the two strands are linked by a single loop [15], or RNA dumbbells [16], made by closing the open end of the hairpin. This last structure retains RNAi activity while providing complete protection from nucleases [16]. Finally, siRNA can also comprise three strands, namely, two 9-13 nt sense strands and the intact antisense strand. This structure is known as small internally segmented interfering RNA [17] (sisiRNA). Some of these modifications have reduced offtarget effects and increased potency (Figure 1(a)). Another architecture not yet explored in siRNA is the branched RNA structure obtained from a central building unit and several branching points that enable the strand growth.

Several strategies can be used to prepare branched RNA structures. Although the synthesis of these compounds is 


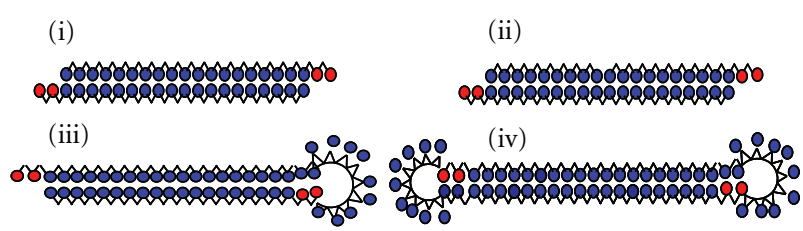

(a)

(v)

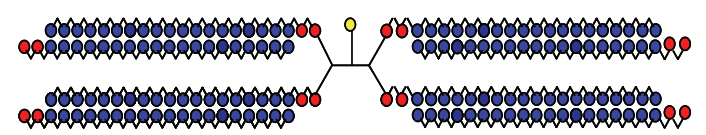

(vi)

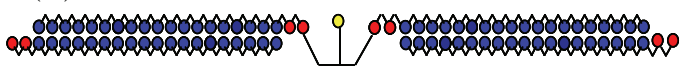

- dT

- RNA nucleosides

o dT or RNA, DNA nucleosides

(b)

FIGURE 1: Duplex RNA architectures for RNA interference. (a) Described previously in the introduction: (i) canonical siRNA antiparallel duplex; (ii) small internally segmented interfering RNA (sisiRNA); (iii) small hairpin RNA ( shRNA); (iv) dumbbell siRNA. (b) Branched siRNA described in this study: (v) four-stranded RNA; (vi) two-stranded RNA.

complex and tedious, commercially available synthons have improved the complexity and yields of these structures.

The assembly of branched nucleic acids on a solid support can be achieved by convergent or divergent strategies. In the former, synthesis of branched oligonucleotides containing two or more identical strands can be achieved by branching derivatives 1,3-diaminopropanol, pentaerythritol, the commercially available symmetric doubler [18-20], or by a ribonucleoside bisphosphoramidite [21] as synthons. In contrast, in the divergent approach two or more distinct strands are prepared with synthons with orthogonal protecting groups or from commercial sources $[20,22]$. In addition, $2^{\prime}$-O-silylribonucleosides have been used to synthesize asymmetric double oligonucleotide strands [23].

Synthetic branched oligonucleotides have been applied for several purposes. Initially, most of the interest in this area was focused on the study of branched oligoribonucleotides as splicing intermediates of eukaryotic mRNAs [24-26]. Moreover, branched oligonucleotides show high affinity for single-strand oligonucleotides to form alternated strand triplexes [27-29]. Recently, branched oligonucleotides have been used as building blocks in the synthesis of new nanostructures [30-34]. Multilabelled oligonucleotides containing branching points have been described to increase the sensitivity of hybridization experiments [35].

Here, we synthesized branched RNA structures (Figure 1(b)) and evaluated their capacity to inhibit the tumour necrosis factor (TNF- $\alpha$ ) protein, which is involved in the apoptosis, inflammation, and immunity processes [36]. We reasoned that branched siRNA could provide a new RNA architecture for RNA interference activity. Given that the use of symmetric branching units is compatible with most of the modifications described to enhance the inhibitory capacity of siRNA, the molecules described here may provide a starting point for further modifications.

\section{Experimental Section}

2.1. Oligonucleotides. The following RNA sequences were obtained from commercial sources (Sigma-Proligo, Dharmacon): sense or passenger scrambled $5^{\prime}$-CAGUCGCGUUUGCGACUGG-dT-dT-3', antisense or guide scrambled $5^{\prime}$-CCAGUCGCAAACGCGACUG-dT-dT-3', antisense or guide anti-TNF- $\alpha$ : $5^{\prime}$-GAGGCUGAGACAUAGGCAC-dTdT- $3^{\prime}$, and sense or passenger anti-TNF- $\alpha$ : $5^{\prime}$-GUGCCUAUGUCUCAGCCUC-dT-dT-3'. RNA monomers in capital letters, dT represents thymidine. The anti-TNF $\alpha$ siRNA was previously described to efficiently downregulate murine TNF $\alpha$ mRNA [36].

Figure 2 refers to the branched RNA structures synthesized in this study. DB stands for the symmetric doubler phosphoramidite obtained from commercial sources (Glen Research). Guanosine was protected with the dimethylaminomethylidene group, cytidine with the acetyl group, and adenosine with the benzoyl group. $t$-Butyldimethylsilyl (TBDMS) group was used for the protection of the $2^{\prime}-\mathrm{OH}$ function of the RNA monomers. The phosphoramidites were dissolved in dry acetonitrile $(0.1 \mathrm{M})$, and a modified cycle was used with increased coupling time to $10 \mathrm{~min}$. Oligoribonucleotide 1 was synthesized on a CPG solid support with a symmetric branching unit of two arms containing two DMT-protected hydroxyl groups, as described in [31]. Oligoribonucleotides 2 and $\mathbf{3}$ were synthesized using standard low-volume polystyrene thymidine columns. After the solidphase synthesis, the supports were treated with concentrated aqueous ammonia-ethanol $(3: 1)$ for $1 \mathrm{~h}$ at $55^{\circ} \mathrm{C}$. After filtration of the supports, the solutions were evaporated to dryness. The residue was dissolved in $85 \mu \mathrm{L}$ of $1 \mathrm{M}$ tetrabutylammonium fluoride (TBAF) in tetrahydrofuran (THF) for $12 \mathrm{~h}$. Then, $85 \mu \mathrm{L}$ of $1 \mathrm{M}$ of triethylammonium acetate was added and the oligoribonucleotides were desalted on a NAP-10 column using water as eluent. The compounds were purified by HPLC under the following conditions. Column: Nucleosil $120-10 \mathrm{C}_{18}(250 \times 4 \mathrm{~mm})$; 20-min linear gradient from $15 \%$ to $100 \% \mathrm{~B}$ (DMT ON conditions); flow rate $3 \mathrm{~mL} / \mathrm{min}$; solution $A$ was $5 \%$ acetonitrile in $0.1 \mathrm{M}$ aqueous triethylammonium acetate (TEAA) buffer and B $70 \%$ acetonitrile in $0.1 \mathrm{M}$ aqueous TEAA. The purified products were analyzed by MALDI-TOF mass spectrometry. Yields ( $0.2 \mu \mathrm{mol}$ scale synthesis) were between 5-10 OD units at $260 \mathrm{~nm}$.

2.2. Thermal Denaturation Studies. The thermal melting curves for duplexes of the oligoribonucleotides 1-3 and their unmodified RNA complementary strands (guide strand) were performed following the absorption change at $260 \mathrm{~nm}$. Samples were heated from $20^{\circ} \mathrm{C}$ to $80^{\circ} \mathrm{C}$, with a linear temperature ramp of $0.5^{\circ} / \mathrm{min}$ in a JASCO V-650 spectrophotometer equipped with a Peltier temperature control. Sample concentration of the samples was around $2 \mu \mathrm{M}$. All the 


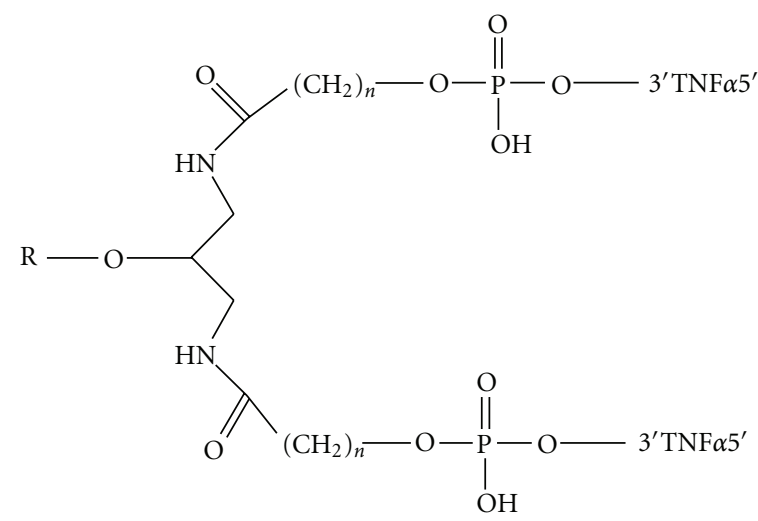

$$
\begin{array}{ll}
\mathrm{R}=\mathrm{COCH}_{2} \mathrm{CH}_{2} \mathrm{CONH}-\mathrm{LCAA}-\mathrm{CPG} n=3 & \mathbf{1}\left(5^{\prime} \mathrm{TNF} \alpha 3^{\prime}\right)_{2}-\mathrm{DB} \\
\mathrm{R}=\mathrm{PO}_{3} \mathrm{H}-\mathrm{Thy} n=5 & \mathbf{2}\left(5^{\prime} \mathrm{TNF} \alpha 3^{\prime}\right)_{2} \text {-DB-dT }
\end{array}
$$

(a)

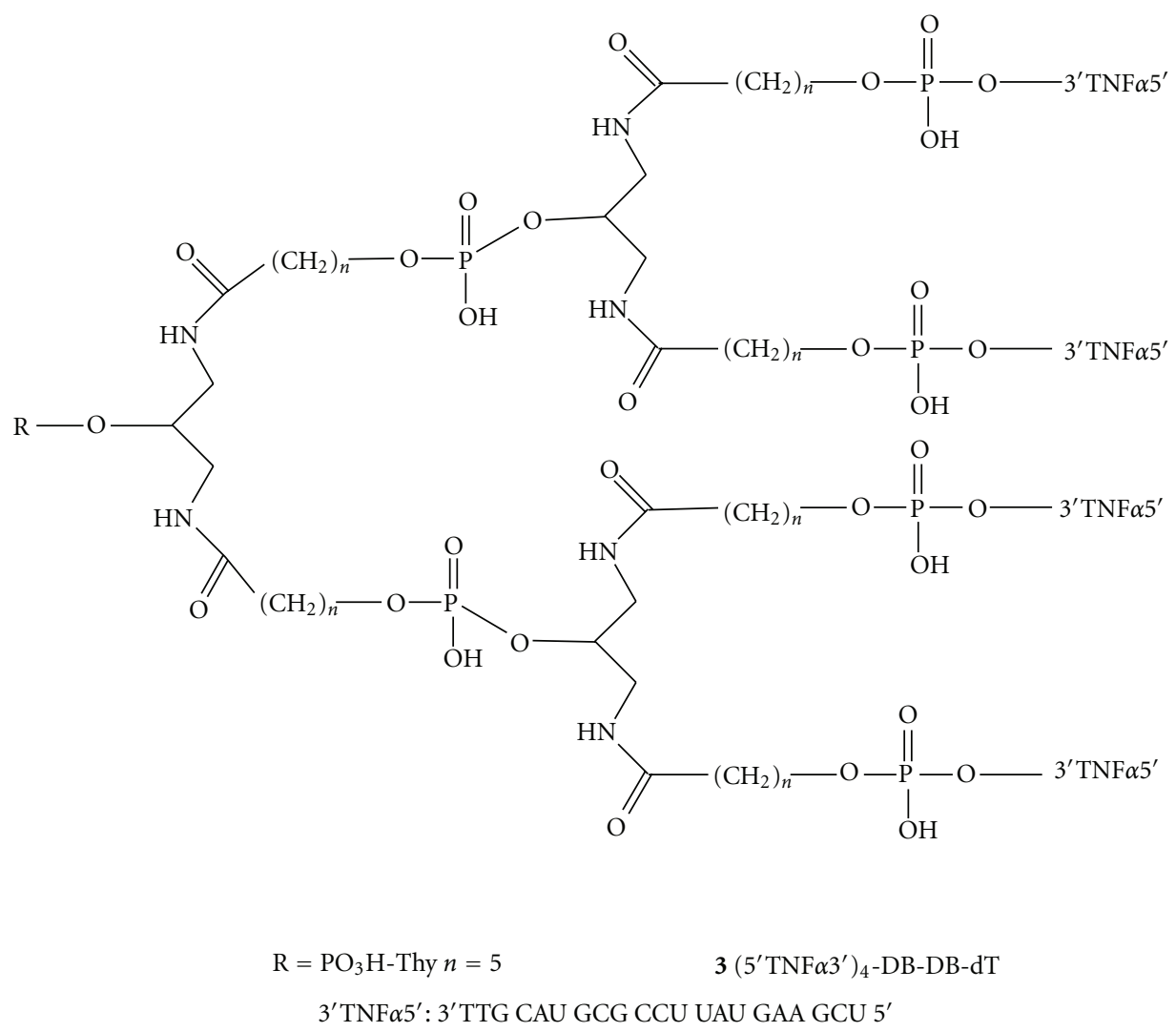

(b)

FIGURE 2: Schematic representation of the chemical structure of the branching units of the oligonucleotides described in this study.

measurements were repeated three times and conducted in $15 \mathrm{mM}$ HEPES $1 \mathrm{mM} \mathrm{Mg}(\mathrm{OAc})_{2}$ and $50 \mathrm{mM} \mathrm{KOAc} \mathrm{pH}$ 7.4.

2.3. Cell Culture, Transfection, and Cellular Assays. HeLa cells were cultured under standard conditions $\left(37^{\circ} \mathrm{C}, 5 \%\right.$ $\mathrm{CO}_{2}$, Dulbecco's Modified Eagle Medium, $10 \%$ fetal bovine serum, $2 \mathrm{mM}$ L-glutamine, supplemented with penicillin
$(100 \mathrm{U} / \mathrm{mL})$ and streptomycin $(100 \mathrm{mg} / \mathrm{mL}))$. All in vitro experiments were performed at $40-60 \%$ confluence. HeLa cells were transfected with $250 \mathrm{ng}$ of a plasmid expressing murine TNF- $\alpha$ using lipofectin (Invitrogen), following the manufacturer's instructions. One hour after transfection cells were transfected with $100 \mathrm{nM}$ double strand concentration of siRNA against TNF- $\alpha$, using oligofectamine (Invitrogen). 


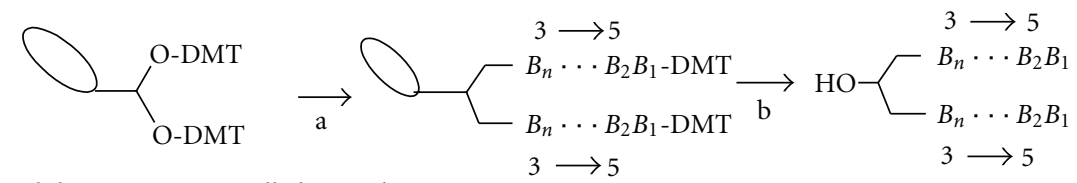

Solid support $=$ controlled pore glass

RNA 1, $(5 \mathrm{TNF} \alpha 3)_{2}$-DB

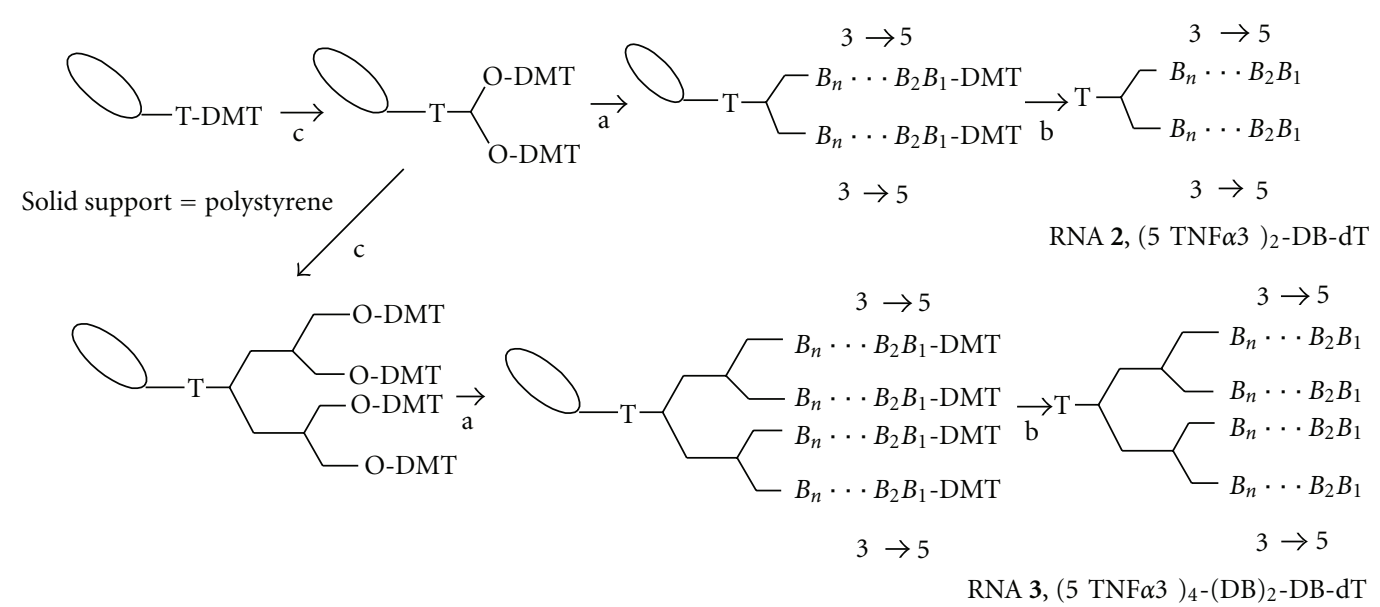

Figure 3: Outline of the synthesis of branched RNA oligonucleotides 1, 2, and 3 with two and four arms with identical sequence. (a) Assembly of the RNA sequence by standard solid-phase methods; (b) removal of protecting groups and release of the RNA molecule from solid support; (c) addition of the symmetrical branching phosphoramidite.

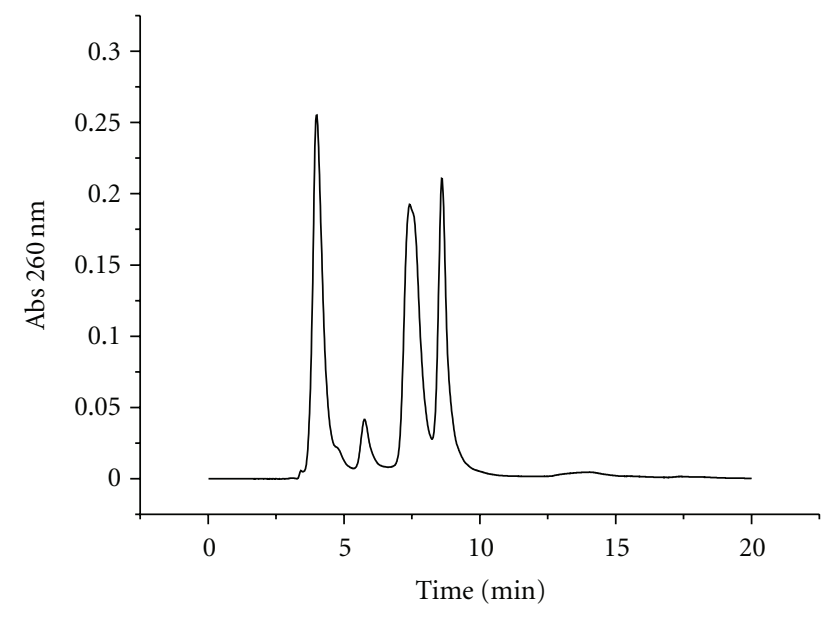

FIGURE 4: HPLC profile of DMT-containing oligonucleotide 2 with two arms. Truncated sequences without DMT groups had a retention of less than 5 min. Fraction eluting between 7-8 min contained oligonucleotides with a single DMT group. The last fraction contained the desired sequence with two DMT groups.

Previously, siRNA duplex annealing was performed by mixing modified $(\mathbf{1}, \mathbf{2}, \mathbf{3})$ and unmodified passenger strands (unm) with the appropriate amount of the corresponding unmodified guide strand.

TNF- $\alpha$ concentration was determined from cell culture supernatant by enzyme-linked immunosorbent assay kit (Bender MedSystems) following the manufacturer's instructions. The inhibitory capacity of the siRNA duplexes is expressed as double strand concentration for comparative purposes. A $100 \mathrm{mM}$ double strand concentration is equivalent to a $50 \mathrm{nM}$ concentration of two-branched siRNA ( 1 or 2 ) and to $25 \mathrm{nM}$ of four-branched siRNA (3).

\section{Results and Discussion}

3.1. Oligonucleotide Synthesis. In order to prepare branched RNA for RNA interference, the potential steric hindrance of the branching unit with RISC must be considered. As the passenger strand is removed from the siRNA duplex upon binding to RISC, we introduced the branching modification at the protruding $3^{\prime}$-end of the sense strand. This position has been demonstrated to allow the introduction of a large number of modifications without affecting the inhibitory capacity of siRNA $[6,7]$. We thus designed branched oligonucleotide sequences 1-3 of the passenger strand of a siRNA directed against TNF$\alpha$ (Figure 2). Sequence 1 was synthesized using a controlled pore glass (CPG) solid support containing a symmetric doubler [31], as shown in Figure 3. Sequences 2 and 3 with two or four strands, respectively, were synthesized on a low-volume polystyrene support (LV200) functionalized with dimethoxytrityl- (DMT-) thymidine. The commercially available symmetric doubler phosphoramidite was used to introduce two and four branches on the $3^{\prime}$-position of the starting thymidine (Figure 3). Sequences were assembled using standard protocols for RNA synthesis. The 2'-OH function of ribonucleosides was protected with the $t$-butyldimethylsilyl (TBDMS) group. Coupling yields, determined by the absorbance of the DMT 


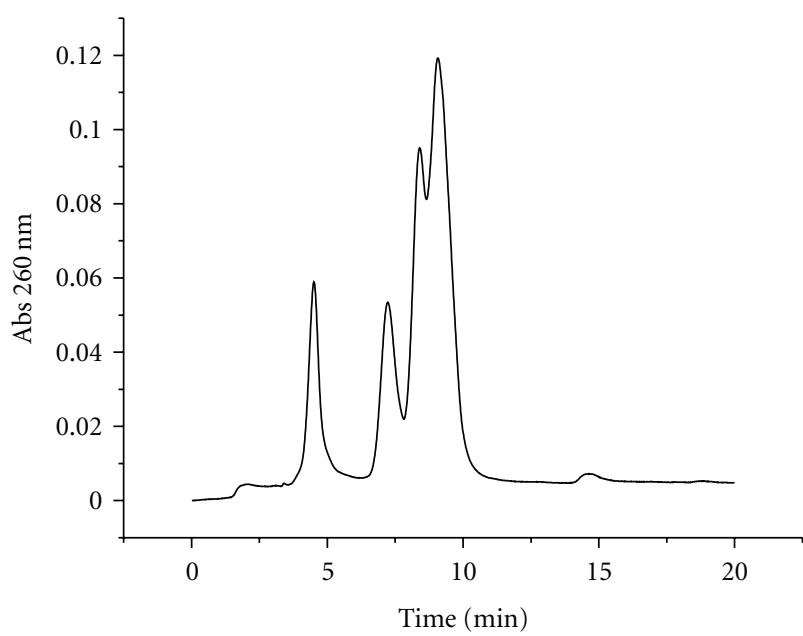

(a)

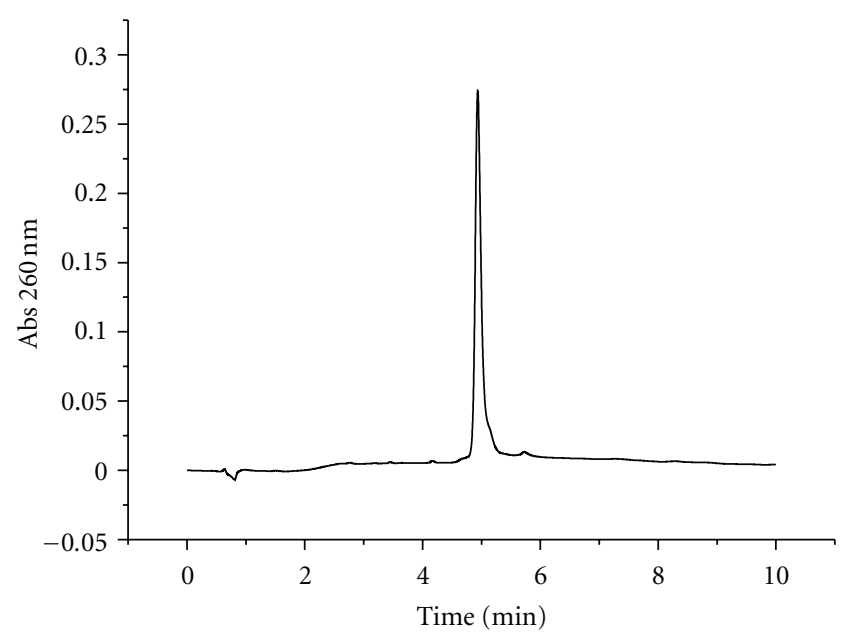

(b)

FIGURE 5: HPLC purification of oligonucleotide 3 with four arms. (a) HPLC profile of DMT-containing oligonucleotide 3. The last fraction contained the desired sequence with four DMT groups; (b) analytical HPLC of purified oligonucleotide 3 after removal of DMT groups.

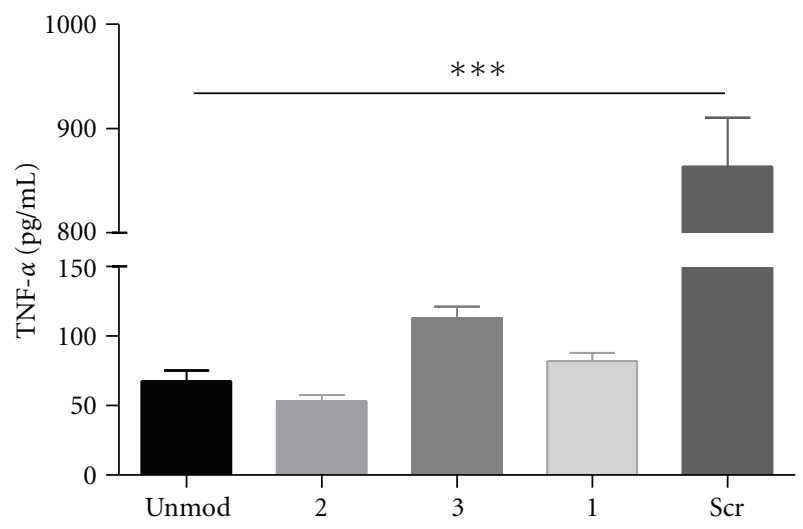

Figure 6: Inhibitory capacity of branched anti-TNF- $\alpha$ siRNAs. The inhibitory capacity of the siRNA duplexes are expressed as double strand concentration for comparative purposes. A 100-nM double strand concentration is equivalent to a concentration of $100 \mathrm{nM}$ of unmodified siRNA duplex, $50 \mathrm{nM}$ of siRNA 1 , and 2 and $25 \mathrm{nM}$ of siRNA 3. Transfection of siRNAs was carried out using oligofectamine. Values are represented as the average $\pm \mathrm{ES}, n=3$ and are compared to a scrambled sequence. ${ }^{* * *} P<.001$, ANOVA Test, Bonferroni post-test.

cation released in each synthesis step, were more efficient (98\%) on low-volume (LV200) polystyrene supports than on CPG support (95\%). After assembly of the sequences, the DMT-containing oligonucleotides were released from the supports with ammonia, and the resulting compounds were treated with fluoride to remove the TBDMS groups. HPLC analysis of the resulting products is shown in Figures 4 and 5 . Several peaks were observed for the synthesis of the two-branch RNA sequences (1 and 2; Figure 4). Truncated sequences without DMT groups eluted between 3-5 min. A fraction containing oligonucleotides with a single DMT group was eluted next, and the last fraction contained the desired sequence with two DMT groups. Mass spectrometry analysis (Table 1) and electrophoresis analysis confirmed the mass and size of the desired branched oligoribonucleotides.

Figure 5 shows the HPLC profile of the mixture obtained in the synthesis of the four-branch RNA sequence (3). In this case, three peaks in the DMT-containing area were observed. Although resolution of these peaks was not as good as in the previous case, the last eluting peak corresponded to the desired tetra-DMT compound (3). The purified compound had the expected molecular weight, was homogeneous by analytical HPLC (Figure 5), and showed the correct migration in polyacrylamide gel electrophoresis (PAGE).

3.2. Thermal Denaturation Studies. The melting temperatures of the branched siRNA duplexes formed by annealing of equimolar amounts of sequences 1-3 with unmodified passenger strand are shown in Table 1. Duplex 1 had the lowest melting temperature, which was $3.5^{\circ} \mathrm{C}$ lower than the unmodified duplex (Table 1). Duplex 2 melted $1.5^{\circ} \mathrm{C}$ lower than the unmodified duplex. In contrast, duplex 3 had similar melting temperatures as the unmodified duplex. The small decrease in melting temperatures of the twobranched siRNA structures is possibly due to a steric effect in the branching point that holds the two duplex strands in close proximity. The four-stranded architecture had a larger separation between strands as a result of the introduction of 3 branching units, thus the resulting duplexes showed greater similarity to the unmodified duplex. Thus we believe that the small destabilizing effect observed in the two-branched RNA duplexes could be optimized in further experiments by adding a linker between the branching unit and the RNA strands, as described by Grimau et al. [31].

3.3. Cell Culture, Transfection, and Cellular Assays.. Tumor necrosis factor (TNF- $\alpha$ ) was selected as a target for RNA interference studies. This protein is a major mediator of apoptosis as well as inflammation and immunity, and it has 
TABLE 1: Mass spectrometry data on modified passenger strand and melting temperatures of siRNA duplexes formed by oligonucleotides 1, 2, and 3 and the linear unmodified control sequences. Buffer conditions: $15 \mathrm{mM}$ HEPES, $1 \mathrm{mM}$ magnesium acetate, $50 \mathrm{mM}$ potassium acetate $\mathrm{pH} 7.4$.

\begin{tabular}{|c|c|c|c|c|c|}
\hline $\mathrm{N}^{\circ}$ & oligonucleotides & MS (expected) & MS (found) & $\operatorname{Tm}\left({ }^{\circ} \mathrm{C}\right)$ & $\Delta T\left({ }^{\circ} \mathrm{C}\right)$ \\
\hline 1 & $\left(5^{\prime} \mathrm{TNF} \alpha 3^{\prime}\right)_{2}-\mathrm{DB}$ & 13508 & 13504 & 79.8 & -3.5 \\
\hline 2 & $\left(5^{\prime} \mathrm{TNF} \alpha 3^{\prime}\right)_{2}$-DB-dT & 13842 & 13847 & 82.5 & -1.7 \\
\hline 3 & $\left(5^{\prime} \mathrm{TNF} \alpha 3^{\prime}\right)_{4}-(\mathrm{DB})_{2}-\mathrm{DB}-\mathrm{dT}$ & 27798 & 27823 & 84.3 & +0.1 \\
\hline Unmodified & Passenger TNF $\alpha$ & n.d. & n.d. & 84.2 & 0 \\
\hline
\end{tabular}

been implicated in the pathogenesis of a wide spectrum of human diseases. Consequently, inhibition of this protein is of particular relevance. Modified oligoribonucleotides (1-3) were annealed with equimolar amounts of the unmodified guide, and the resulting duplexes were used to inhibit the expression of TNF- $\alpha$ gene. HeLa cells were transfected first with the murine TNF- $\alpha$ plasmid using lipofectin, and $1 \mathrm{~h}$ later they were cotransfected with the siRNA duplex using oligofectamine. After $24 \mathrm{~h}$, cellular TNF- $\alpha$ production was analyzed by enzyme-linked immunosorbent assay (ELISA). The inhibitory capacity of the siRNA duplexes is shown in Figure 6. To compare the efficiency of each siRNA to inhibit TNF- $\alpha$, we normalized the data taking in account the number of strands of each siRNA. Thus, a $100 \mathrm{nM}$ double strand concentration is equivalent to $100 \mathrm{nM}$ of unmodified siRNA duplex, $50 \mathrm{nM}$ of siRNA 1 , and 2 , and $25 \mathrm{nM}$ of siRNA 3. Figure 6 shows that the inhibitory capacity of the branched structures was maintained similar to that of the unmodified duplex. This result indicates that the branched siRNAs described here are compatible with RNA interference machinery, and thus the RISC complex binds to branched RNA structures in a similar way as to the linear RNA duplexes shown in Figure 1. Two-stranded RNA duplexes (1 and 2) were more efficient than four-stranded ones (3). In addition, siRNA 1 showed slightly greater efficiency at inhibiting TNF$\alpha$ than siRNA duplex 2 . This small difference may be related to the lower melting temperature of the former (Table 1).

\section{Conclusions}

For several years, research has focused on chemical modifications and delivery technologies to improve the pharmacokinetic properties of siRNA. Many of the chemically modified siRNA with interesting inhibitory capacity contain one or multiple modifications in the sugar, nucleobases, and phosphate linkages or at the $3^{\prime}$ - or $5^{\prime}$-ends. In addition to these modifications, duplex architecture of siRNA itself is also relevant, and several modifications have been reported to show satisfactory inhibitory capacity. Here we demonstrate that branched siRNA is compatible with RNAi and that, when transfected with cationic lipids, siRNA has similar inhibitory capacity than unmodified duplex siRNA. Although the potency of branched siRNA containing two or four strands was not increased, we consider it a suitable starting point for further development. Given that the method described here is compatible with most of the RNA modifications described to date, these compounds may be further functionalized to obtain more potent siRNA derivatives. In addition, they offer an internal mid position that could be suitable for attachment to delivery systems. In this regard, optimization of the branching approach for the synthesis of asymmetric branched siRNAs may lead to the development of siRNA for the combined inhibition of multiple targets. These asymmetric siRNA duplexes carrying two RNA sequences attached or bound to an appropriate delivery system will insure the $1: 1$ ratio of two RNA sequences for the combined inhibition of two genes that may improve the treatment of a particular disease.

\section{Acknowledgments}

This paper was supported by the Spanish Ministry of Education (Grants BFU2007-63287, CTQ2010-20541) and the Generalitat de Catalunya (2009/SGR/208). CIBER-BBN is an initiative funded by the VI National R\&D\&i Plan 20082011, Iniciativa Ingenio 2010, Consolider Program, and CIBER Actions and financed by the Instituto de Salud Carlos III with assistance from the European Regional Development Fund.

\section{References}

[1] A. de Fougerolles, H. P. Vornlocher, J. Maraganore, and J. Lieberman, "Interfering with disease: a progress report on siRNA-based therapeutics," Nature Reviews Drug Discovery, vol. 6, no. 6, pp. 443-453, 2007.

[2] D. A. Braasch, S. Jensen, Y. Liu et al., "RNA interference in mammalian cells by chemically-modified RNA," Biochemistry, vol. 42, no. 26, pp. 7967-7975, 2003.

[3] K. Tiemann and J. J. Rossi, "RNAi-based therapeutics-current status, challenges and prospects," EMBO Molecular Medicine, vol. 1, no. 3, pp. 142-151, 2009.

[4] F. Eberle, K. Gießler, C. Deck et al., "Modifications in small interfering RNA that separate immunostimulation from RNA interference," Journal of Immunology, vol. 180, no. 5, pp. 32293237, 2008.

[5] A. L. Jackson, S. R. Bartz, J. Schelter et al., "Expression profiling reveals off-target gene regulation by RNAi," Nature Biotechnology, vol. 21, no. 6, pp. 635-637, 2003.

[6] J. K. Watts, G. F. Deleavey, and M. J. Damha, "Chemically modified siRNA: tools and applications," Drug Discovery Today, vol. 13, no. 19-20, pp. 842-855, 2008.

[7] YA. L. Chiu and T. M. Rana, "siRNA function in RNAi: a chemical modification analysis," RNA, vol. 9, no. 9, pp. 10341048, 2003.

[8] R. A. Blidner, R. P. Hammer, M. J. Lopez, S. O. Robinson, and W. T. Monroe, "Fully 2'-deoxy-2'-fluoro substituted nucleic acids induce RNA interference in mammalian cell culture," 
Chemical Biology and Drug Design, vol. 70, no. 2, pp. 113-122, 2007.

[9] J. Elmén, H. Thonberg, K. Ljungberg et al., "Locked nucleic acid (LNA) mediated improvements in siRNA stability and functionality," Nucleic Acids Research, vol. 33, no. 1, pp. 439447, 2005.

[10] M. Terrazas and E. T. Kool, "RNA major groove modifications improve siRNA stability and biological activity," Nucleic Acids Research, vol. 37, no. 2, pp. 346-353, 2009.

[11] J. Soutschek, A. Akinc, B. Bramlage et al., "Therapeutic silencing of an endogenous gene by systemic administration of modified siRNAs," Nature, vol. 432, no. 7014, pp. 173-178, 2004.

[12] S. M. Elbashir, J. Harborth, W. Lendeckel, A. Yalcin, K. Weber, and T. Tuschl, "Duplexes of 21-nucleotide RNAs mediate RNA interference in cultured mammalian cells," Nature, vol. 411, no. 6836, pp. 494-498, 2001.

[13] F. Czauderna, M. Fechtner, S. Dames et al., "Structural variations and stabilising modifications of synthetic siRNAs in mammalian cells," Nucleic Acids Research, vol. 31, no. 11, pp. 2705-2716, 2003.

[14] D. H. Kim, M. A. Behlke, S. D. Rose, MI. S. Chang, S. Choi, and J. J. Rossi, "Synthetic dsRNA Dicer substrates enhance RNAi potency and efficacy," Nature Biotechnology, vol. 23, no. 2, pp. 222-226, 2005.

[15] D. Siolas, C. Lerner, J. Burchard et al., "Synthetic shRNAs as potent RNAi triggers," Nature Biotechnology, vol. 23, no. 2, pp. 227-231, 2005.

[16] N. Abe, H. Abe, and Y. Ito, "Dumbbell-shaped nanocircular RNAs for RNA interference," Journal of the American Chemical Society, vol. 129, no. 49, pp. 15108-15109, 2007.

[17] J. B. Bramsen, M. B. Laursen, C. K. Damgaard et al., "Improved silencing properties using small internally segmented interfering RNAs," Nucleic Acids Research, vol. 35, no. 17, pp. 5886-5897, 2007.

[18] V. A. Korshun, N. B. Pestov, E. V. Nozhevnikova, I. A. Prokhorenko, S. V. Gontarev, and Y. A. Berlin, "Reagents for multiple non-radioactive labelling of oligonucleotides," Synthetic Communications, vol. 26, no. 13, pp. 2531-2547, 1996.

[19] M. S. Shchepinov, A. J. Udalova, A. J. Bridgman, and E. M. Southern, "Oligonucleotide dendrimers: synthesis and use as polylabeled DNA probes," Nucleic Acids Research, vol. 25, no. 22, pp. 4447-4454, 1997.

[20] M. S. Shchepinov and E. M. Southern, "The synthesis of branched oligonucleotide structures," Bioorganicheskaya Khimiya, vol. 24, no. 10, pp. 794-797, 1998.

[21] M. J. Damha and K. K. Ogilvie, "Synthesis and spectroscopic analysis of branched RNA fragments: messenger RNA splicing intermediates," Journal of Organic Chemistry, vol. 53, no. 16, pp. 3710-3722, 1988.

[22] E. Utagawa, A. Ohkubo, M. Sekine, and K. Seio, "Synthesis of branched oligonucleotides with three different sequences using an oxidatively removable tritylthio group," Journal of Organic Chemistry, vol. 72, no. 22, pp. 8259-8266, 2007.

[23] R. S. Braich and M. J. Damha, "Regiospecific solid-phase synthesis of branched oligonucleotides. Effect of vicinal 2,5'(or 2',3'-) and 3',5'-phosphodiester linkages on the formation of hairpin DNA," Bioconjugate Chemistry, vol. 8, no. 3, pp. 370-377, 1997.

[24] M. J. Damha, K. Ganeshan, R. H.E. Hudson, and S. V. Zabarylo, "Solid-phase synthesis of branched oligoribonucleotides related to messenger RNA splicing intermediates," Nucleic Acids Research, vol. 20, no. 24, pp. 6565-6573, 1992.
[25] S. Carriero and M. J. Damha, "Inhibition of pre-mRNA splicing by synthetic branched nucleic acids," Nucleic Acids Research, vol. 31, no. 21, pp. 6157-6167, 2003.

[26] M. Grøtli, R. Eritja, and B. Sproat, "Solid-phase synthesis of branched RNA and branched DNA/RNA chimeras," Tetrahedron, vol. 53, no. 33, pp. 11317-11346, 1997.

[27] Y. Ueno, M. Takeba, M. Mikawa, and A. Matsuda, "Nucleosides and nucleotides. 182. Synthesis of branched oligodeoxynucleotides with pentaerythritol at the branch point and their thermal stabilization of triplex formation," Journal of Organic Chemistry, vol. 64, no. 4, pp. 1211-1217, 1999.

[28] M. D. Sorensen, M. Meldgaard, V. K. Rajwanshi, and J. Wengel, "Branched oligonucleotides containing bicyclic nucleotides as branching points and DNA or LNA as triplex forming branch," Bioorganic and Medicinal Chemistry Letters, vol. 10, no. 16, pp. 1853-1856, 2000.

[29] A. Aviñó, M. G. Grimau, M. Frieden, and R. Eritja, "Synthesis and triplex-helix-stabilization properties of branched oligonucleotides carrying 8-aminoadenosine moieties," Helvetica Chimica Acta, vol. 87, no. 2, pp. 303-316, 2004.

[30] M. S. Shchepinov, K. U. Mir, J. K. Elder, M. D. FrankKamenetskii, and E. M. Southern, "Oligonucleotide dendrimers: stable nano-structures," Nucleic Acids Research, vol. 27, no. 15, pp. 3035-3041, 1999.

[31] M. G. Grimau, D. Iacopino, A. Aviñó et al., "Synthesis of branched oligonucleotides as templates for the assembly of nanomaterials," Helvetica Chimica Acta, vol. 86, no. 8, pp. 2814-2826, 2003.

[32] S. E. Stanca, A. Ongaro, R. Eritja, and D. Fitzmaurice, "DNAtemplated assembly of nanoscale architectures," Nanotechnology, vol. 16, no. 9, pp. 1905-1911, 2005.

[33] H. Yang and H. F. Sleiman, "Templated synthesis of highly stable, electroactive, and dynamic metal-DNA branched junctions," Angewandte Chemie-International Edition, vol. 47, no. 13, pp. 2443-2446, 2008.

[34] M. Scheffler, A. Dorenbeck, S. Jordan, M. Wüstefeld, and G. Von Kiedrowski, "Self-assembly of trisoligonucleotidyls: the case for nanoacetylene and nano-cyclobutadiene," Angewandte Chemie - International Edition, vol. 38, no. 22, pp. 3312-3315, 1999.

[35] T. Horn, C. A. Chang, and M. S. Urdea, "Chemical synthesis and characterization of branched oligodeoxyribonucleotides (bDNA) for use as signal amplifiers in nucleic acid quantification assays," Nucleic Acids Research, vol. 25, no. 23, pp. 48424849, 1997.

[36] D. R. Sørensen, M. Leirdal, and M. Sioud, “Gene silencing by systemic delivery of synthetic siRNAs in adult mice," Journal of Molecular Biology, vol. 327, no. 4, pp. 761-766, 2003. 

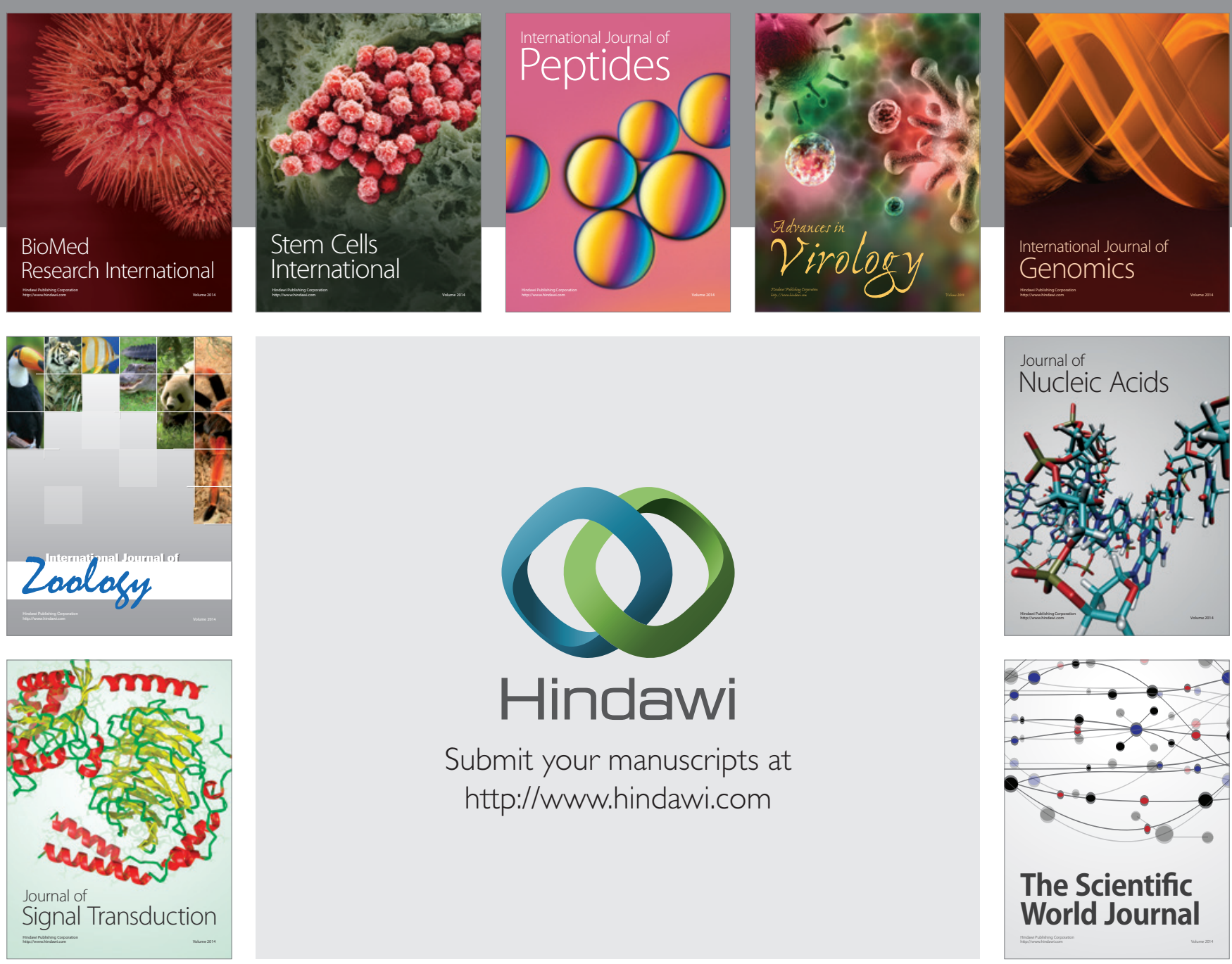

Submit your manuscripts at

http://www.hindawi.com
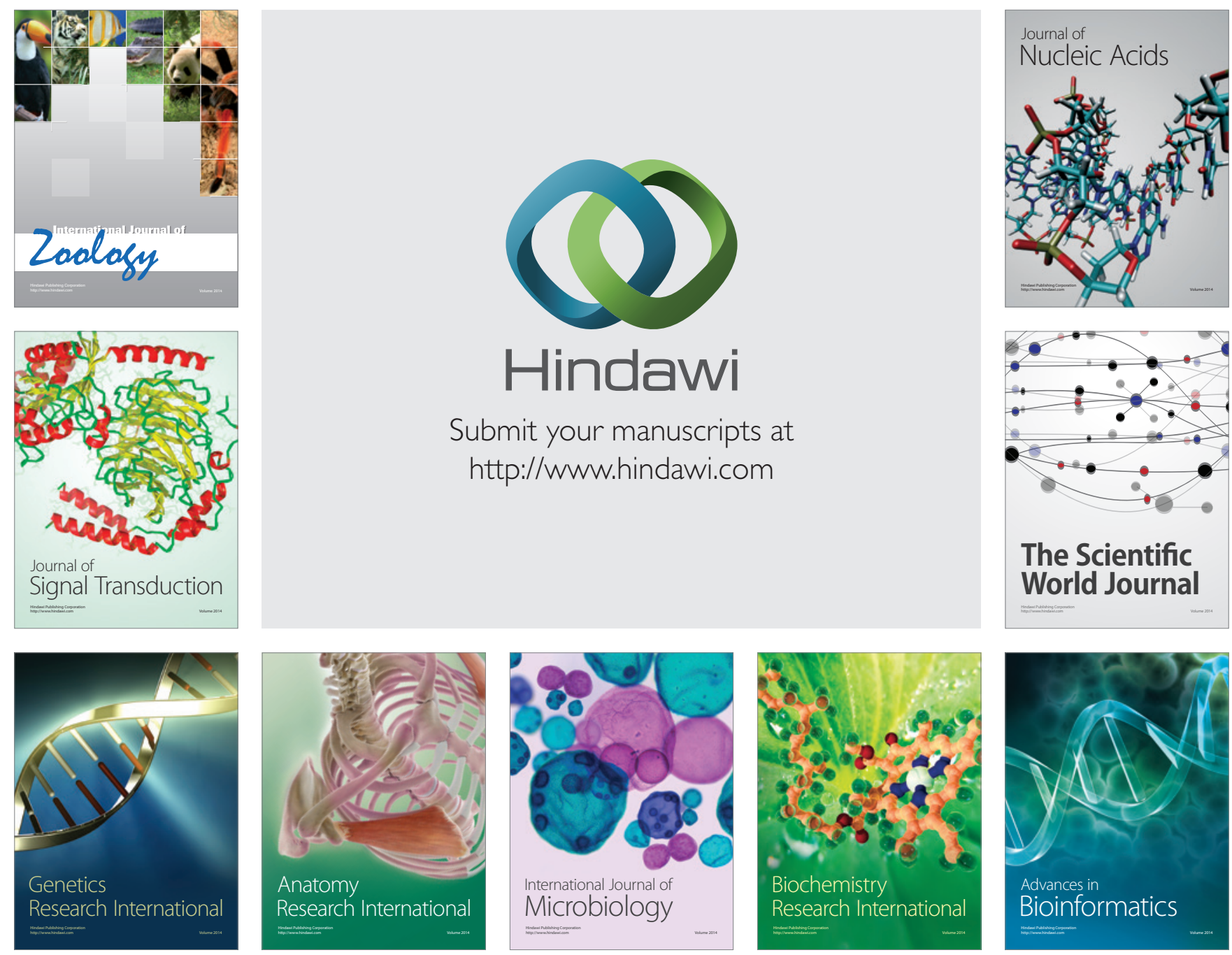

The Scientific World Journal
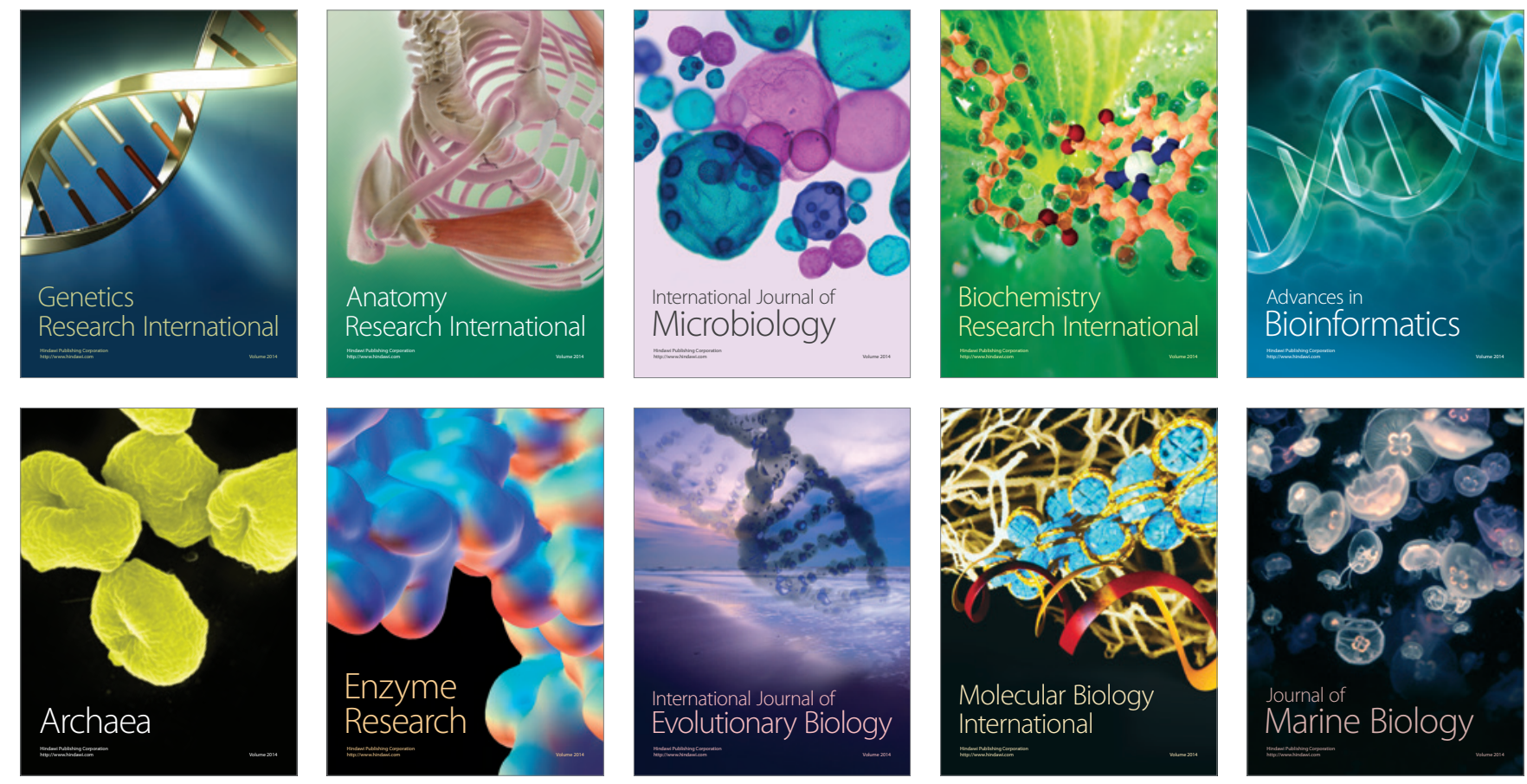